\title{
Electromagnetic Radiation Influences on Rheological Parameters of Rats' Blood
}

\section{Mai I. El-kaliuoby}

Physics \& Chemistry Department, Faculty of Education, Alexandria University, Alexandria, Egypt

\begin{tabular}{|c|c|}
\hline ARTICLE INFO & ABSTRACT \\
\hline Article history: & \multirow{7}{*}{$\begin{array}{l}\text { The present work aims at studying the alterations in blood viscoelasticity and hematological } \\
\text { parameters as a result of the exposure to an electric field }(50 \mathrm{~Hz}-4 \mathrm{kV} / \mathrm{m}-8 \mathrm{~h} / \mathrm{d}) \text {, a magnetic } \\
\text { field }(50 \mathrm{~Hz}-\mathbf{- 0 . 3} \mathrm{mT}-8 \mathrm{~h} / \mathrm{d}) \text { and high energy photon }\left(6 \mathrm{MeV} ; 0.002 \mathrm{~A}^{\circ}-1 \mathrm{rad}\right) \text {. The blood tissue } \\
\text { was chosen as biomarker for the direct and delay exposure evaluations, whereas its viscosity } \\
\text { coefficient as function of the shear rate was monitored and its mechanical characteristics as } \\
\text { function of osmotic pressure was measured. In addition, the hematological parameters were } \\
\text { observed for all collected blood samples and correlated to the blood viscoelasticity. The } \\
\text { obtained results showed remarkable effects on the studied blood parameters even at short } \\
\text { exposure periods and /or after delayed exposure effects. From the present results it may be } \\
\text { concluded that the exposure to electric and magnetic fields at extremely low frequency range } \\
\text { has hazardous effect not less than the ionizing radiation at very low dose. Our findings } \\
\text { indicated that maximum deteriorative effects resulted due to exposure to magnetic field } \\
\text { (30 days) whereas the blood viscosity coefficient, RBCs elastic limit, and hemoglobin were } \\
\text { decreased relative to the control by }-38 \% \text {, }-30 \% \text { and }-25 \% \text { respectively. Moreover, the } \\
\text { changes in blood viscoelasticity and hematological parameters, as a result of the exposure } \\
\text { even after } 45 \text { days post exposure support the hazardous effects of such fields. The need for } \\
\text { new recommendations for exposure to such fields and frequent blood checkup should be done } \\
\text { from time to another especially for residents who are exposed for long times. }\end{array}$} \\
\hline Received: $18^{\text {th }}$ Oct. 2020 & \\
\hline Accepted: $14^{\text {th }}$ Apr. 2021 & \\
\hline Keywords: & \\
\hline $\begin{array}{l}\text { Electromagnetic Radiations, } \\
\text { High Energy Photons, } \\
\text { Blood Viscosity, }\end{array}$ & \\
\hline Osmotic Fragility, & \\
\hline Hematological Parameters. & \\
\hline
\end{tabular}

\section{INTRODUCTION}

The expansion of using electric powers in industrialized countries and the parallel increase of environmental exposure to extremely low frequency electromagnetic fields ELF-EMF lead to apprehension of the hazard of these fields on the human health. Such exposures may cause several hazardous health consequences such as headache, fatigue, depression and hyperactivity [1]. In this regards, many studies were done for knowing the possible hazard effects attributed to these fields [2-12].

The ELF magnetic fields (ELF MF) cause lipid peroxidation due to overproduction of reactive oxygen species (ROS) [13,14]. ROS can be an important intercessor of cell structures damage, including lipids and membranes, proteins, and DNA $[15,16]$. In spite of the fact that the living organism has defensive systems against free radicals, these antioxidant defense systems can be deteriorated by the effect of magnetic field, which leads to an oxidative stress which gives rise to functional and morphological disturbances in red blood cells. [17] Blood, as a fundamental part of the immune system and one of the functional tissues, can deliver oxygen and nutrition to the vital parts in the body which was chosen to be investigated under exposure conditions [18]. The blood flow, which is considered as non-Newtonian fluids, through blood vessels is a very complicated phenomenon due to physical and physicochemical properties of the blood and the structure of the circulatory system. Rheological characteristics of the blood depend mainly on two parameters: viscosity and elasticity. The main factors determining blood viscosity are: the hematocrit value, erythrocytes aggregability and deformability, and the plasma viscosity [19].

In this regards, the study of the exposure of ELF MF $(7 \mathrm{mT}-50 \mathrm{~Hz}-24 \mathrm{~h})$ on hematological parameters in vivo experiments on blood cell was carried out and the results indicated disturbance white blood cells WBCs, lymphocytes, and hematocrit [20]. Moreover, blood counts alternation, RBCs aggregations, and change its 
viscosity were obseved. In addition, in other studies the results indicated a significant decrease in RBCs counts, membrane elasticity, permeability, electrical conductivity of hemoglobin, increase of relative permittivity of the blood [21] and changes in the molecular structure of hemoglobin of exposed groups to MF. The blood smears photomicrograph of these groups revealed a distorted shape and staked RBCs forming rouleaux. Such results might be correlated to the magnetic field interactions with blood cells at which might change size and charge on the surface of red blood cells RBCs [22]. On the other hand, other researchers reported that long exposure to Magnetic fields might to induce toxicity of specific organs as the result of RBCs functional failure and deterioration of metabolic activity [23-25]. Low values of Mean Corpuscular Volume (MCV) with loss of the cellular water and a cellular volume contraction were indicated at some researches as the reflection of the effect of EMF on membrane permeability. That was accompanied by an increase of the Mean Corpuscular Hemoglobin $(\mathrm{MCH})$ with preserving the cellular respiratory capacity. Many of previous Experimental models showed a significant elevation in WBCs count which might be reflector to an inflammation [26,27]. Alterations in the calcium signaling pathways have been recorded in response to the effects of EMF exposure, calcium channels and receptors on the cell membrane, which affects the response of mitochondrial calcium reaction as the energy source of the cell [10].

Ionizing radiation (IR) has a sufficient amount of energy to induce physical symptomatology within minutes of exposure, appearing as the acute radiation syndrome (ARS) [28]. Radiation was shown to affect the biochemical structure of the red blood cells the membrane. It increases membrane cholesterol level, causes oxidation of membrane protein, thiol groups and lipid peroxidation, and fragility of membrane permeability barrier [29]. The effect of low exposure doses of gamma ray at doses of $0.055 \mathrm{~Gy}, 0.11 \mathrm{~Gy}$ and $0.165 \mathrm{~Gy}$ on some hematological parameters of albino rats was investigated. The increase of gamma ray doses of rats led to a significant decrease in the RBCs and $\mathrm{Hb}$ were resulted. In addition, it was found $\mathrm{MCV}$ and $\mathrm{MCH}$ increase with increasing the exposure dose as well as a significant reduction in the platelets. But WBCs count, lymphocytes count, monocytic, neutrophils, esinophiles and basophiles respective controls were decreased with the increase of the gamma ray doses of rats [30]. Recently the effect of exposure to magnetic fields gained more attention than electric fields and so, our aim was to evaluate the biological hazardous effects of both fields. Furthermore, the impact of exposure to both fields and exposure to high energy photons on rheological the blood as main circulatory system was tested to highlight the possible bio-alterations. The present work aimed at studying the effect of the extremely low frequency electric $(50 \mathrm{~Hz}-4 \mathrm{kV} / \mathrm{m}-8 \mathrm{~h} / \mathrm{d})$ and magnetic field $(50 \mathrm{~Hz}-0.3 \mathrm{mT}-$ $8 \mathrm{~h} / \mathrm{d})$ and high energy photon $\left(6 \mathrm{MeV} ; 0.002 \mathrm{~A}^{\circ}-1 \mathrm{rad}\right)$ on the blood rheological properties and hematological parameters.

\section{MATERIALS AND METHODS}

In the present study, 150 male albino rats of average $170 \pm 15 \mathrm{~g}$ weight were used and divided into six groups. Two groups of forty rats were exposed to $(4 \mathrm{kV} / \mathrm{m}, 50 \mathrm{~Hz}-$ $8 \mathrm{~h} / \mathrm{d}$ ) at two different exposure periods. Animals of first group were exposed for period of 7-days and the other one exposed for a period of 30-days. For each group ten animals were sacrificed immediately after exposure and the remaining ten were left in normal environmental condition 45-days post the exposure and then sacrificed. Similarly, two groups of forty animals were exposed to magnetic field $(0.3 \mathrm{mT}, 50 \mathrm{~Hz}-8 \mathrm{~h} / \mathrm{d})$ successively during 7 days (20 rats) and 30 days (20 rats). As mentioned before ten animals from each group were sacrificed immediately and the other ten were left in normal environmental condition and sacrificed 45 days post the exposure. In addition, another one group of twenty animals was exposed to high energy photon $(6 \mathrm{MeV}-1 \mathrm{rad})$ emitted from a linear accelerator (LINAC) at Faculty of Medicine, Alexandria University, Egypt. On the same manner, ten rats were immediately sacrificed after exposure and the other ten rats were left 45 days' post exposure and then sacrificed. Finally, control group of 50 animals were housed in normal environmental conditions, didn't receive any treatment, kept inside the lab at average temperature of $25^{\circ} \mathrm{C}$ and 5 rats were sacrificed at every exposure condition as sham group.

The exposure to electromagnetic fields was utilized by using electric and magnetic exposure facilities. The electric exposure facility was adapted to generate electric field of $4 \mathrm{kV} / \mathrm{m}$ through Perspex chamber of dimensions $100 \times 30 \times 35 \mathrm{~cm}^{3}$. The mains output of $50 \mathrm{~Hz}-4 \mathrm{kV}$ was conducted to the exposure chamber directly with the two side aluminum sheets covered by insulating materials to prevent electric shock with animals [31]. The reading of electric field inside exposure chamber was measured over the animal living space and confirmed to be $4 \pm 0.2 \mathrm{kV} / \mathrm{m}$. On the other hand, the magnetic exposure facility was adjusted to give magnetic field of strength $0.3 \mathrm{mT}$ applied over large cylindrical chamber of dimensions $100 \mathrm{~cm}$ long and $60 \mathrm{~cm}$ wide. The field was generated by using mains of $50-\mathrm{Hz}-0.8$ A connected directly with four solenoid coils (48 turns-2 $\mathrm{mm}$ ) of length $63 \mathrm{~cm} /$ each. The animals were placed inside Arab J. Nucl. Sci. Appl., Vol. 54, 3, (2021) 
Perspex cages of dimensions $30 \times 40 \times 35 \mathrm{~cm}^{3}$ on a shelf inside the central axis of the cylindrical chamber. On the other hand, the exposure to high energy photons $(6 \mathrm{MeV}$; $\left.0.002 \mathrm{~A}^{\mathrm{o}}-1 \mathrm{rad}\right)$ was obtained by exposing animals to Elekta Linear accelerator (LINAC) at source to surface distance (SSD) of $100 \mathrm{~cm}$ and it was adjusted to give collimator and couch angles of $0^{0}$.

Whole blood samples were collected immediately after sacrificing to further rheological, mechanical and biochemical analysis. The Brookfield DV-II Programmable Rheometer cone \& plate (Spindle SC4-18/ Sample chamber SC4-13 (p)) manufactured by a Brookfield company in the USA measures blood shear stress and viscosity $(\mathrm{cP})$ under specific shear rates. The rheometer was provided with circulating water path for temperature control. Then after the viscosity coefficient values versus each shear rate were plotted for all blood samples and so, viscosity curves were obtained. The mechanical properties of blood samples were measured by monitoring hemolysis of blood cells under osmotic effect. Osmotic fragility test of whole blood was performed for control and experimental groups by adding $0.05 \mathrm{ml}$ of blood sample to varying concentrations [0\%-100\%] of buffered sodium chloride solution (normal saline $0.9 \% \mathrm{NaCl}$ ). The solutions allowed to incubate at room temperature for a period of $30 \mathrm{~min}$, then remix the test tubes gently and centrifuge at 3000 r.p.m (centrifugal model 800- 4000/min, made in China). Then after the hemolysis of supernatant was determined by taking the readings of absorbance by means of spectrophotometer (UV/visible spectrophotometer LKB-Novaspec, made in England). The biochemical parameters (Red blood cells RBCs, Hemoglobin $\mathrm{Hb}$, Hematocrit $\mathrm{HCT}$, mean corpuscular volume $\mathrm{MCV}$, mean corpuscular Hemoglobin $\mathrm{MCH}$, and Mean Corpuscular Hemoglobin Conc. MCHC and white blood cells WBCs) were measured for samples under investigations as adapted by [32]. Statistical analysis was performed with SPSS 8.0 package (SPSS Inc., Chicago, IL). The analysis of differences between exposed groups and control groups for each variable was done by using independent sample $t$ test.

\section{RESULTS AND DISCUSSION}

In the present work, a study of biophysical parameters of circulating tissue was done to evaluate the effect of ionizing radiation at very low dose and the effect of nonionizing radiation to compare its hazardous impacts. The blood tissue was chosen to be a biomarker for the radiation effects and its rheological, mechanical and biochemical characteristics were studied. The direct effect of exposure to electric, magnetic and high energy photons on whole blood viscosity was obtained at different shear rates as shown in Figure(1). The obtained curves showed same decreasing response of blood viscosity coefficient as much as the shear rates increased for all studied samples. The resulted curves indicated that the blood viscosity of all exposed samples showed clear shift to lower values than control one. It is worth to state that the maximum decrease of blood viscosity for samples exposed to MF-30days and followed by samples exposed to high energy photons. Figure (2) shows the viscosity curves for blood samples collected 45 days' post exposure to study the possible effects of the exposure on the new blood generation. The obtained curves depicted enhancement in the blood vitality to come closer to the original state but still with remaining shift specially samples exposed to high energy photons. For analysis purpose the relative percentage of change in viscosity coefficient values were calculated relative to control ones. The reference control value was taken to be $100 \%$ and the other coefficient values were calculated as percentages [(control coefficient value -treated coefficient value/control coefficient value) $* 100]$. The obtained data at low shear rate $\left(66 \mathrm{~S}^{-1}\right)$ for samples collected after exposure directly indicated significant shift to lower values relative to control after exposure to MF-30 days, high energy photons and EF-30 days by $-38 \%,-36 \%$ and $-30 \%$ respectively. The study of relative changes in viscosity coefficient values for samples collected 45 days' post exposure didn't show complete recovery and indicated remaining depression in the viscosity coefficient by $-20 \%,-10 \%$ and $-7 \%$ after exposure to high energy photons, MF-30 days and EF-30 days respectively. It is worthy to state that the effect of exposure on the viscosity coefficient values at higher shear rate $\left(264 \mathrm{~S}^{-1}\right)$ showed similar correspondence with same effect order as the lower one.

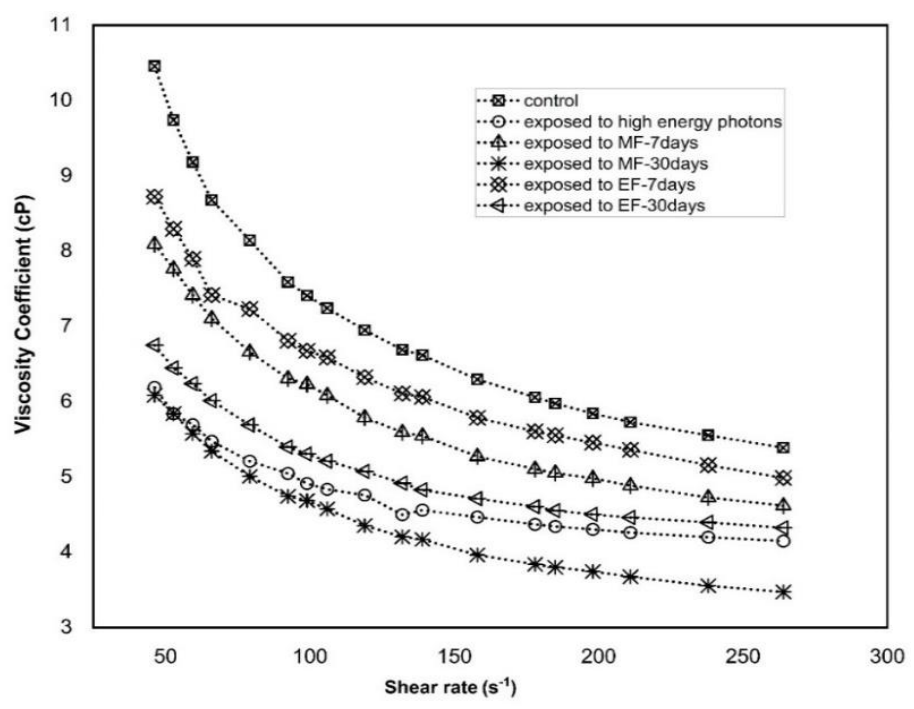

Fig. (1): The direct exposure effect in blood viscosity coefficient values for exposed and control samples as a function of shear rate 


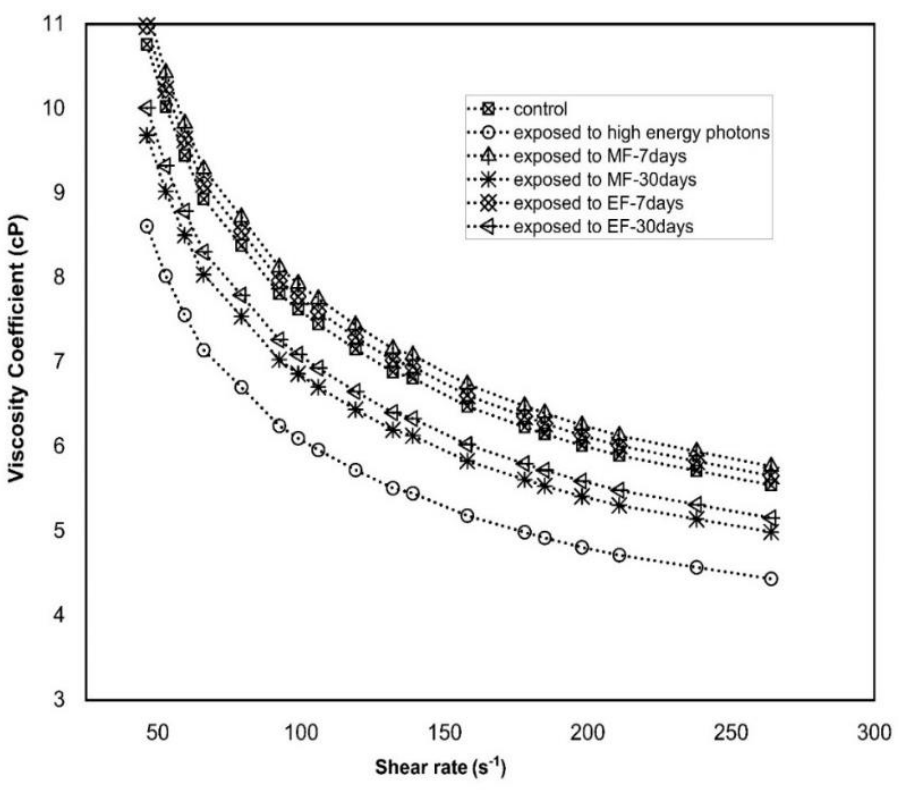

Fig. (2): the delayed exposure effect in blood viscosity coefficient values for exposed and control samples as a function of shear rate.

Of note that the flow of blood through vessels is very complicated process at which it needs the blood to be viscoelastic material that exhibit different shear stresses without losing its heterostructure and preserve its vital contents. To this end the blood flow needs not only the viscosity parameter which defined as the resistance to flow but also, the elasticity parameters which defined as the resistance of blood to be deformed. The former findings showed remarkable effect of the exposure in the blood rheological characteristics as a result of significant structural alterations. The study of blood osmotic fragility may indicate the possible changes in the ionic permeability of blood cell membrane and so, its elasticity. The blood has the ability to be folded several times to pass through narrow capillaries smaller than its diameter to feed the proposed organs [32]. The elasticity of blood cells plays a major role in the folding process and so, study of osmotic fragility at different salt concentrations to monitor its ability to uptake high concentrations without rupture. Figures (3 and 4) show the hemolysis of blood cells under osmotic pressures at different $\mathrm{NaCl}$ concentrations for samples collected after exposure directly and 45 days' post exposure respectively. The obtained data over all exposed samples illuminated shift in the hemolysis to be at higher concentrations than control one. The maximum shift in the hemolysis was determined for samples exposed to high energy photons and followed by samples exposed to MF-30 days which in resemblance to the viscosity data. Remarkable enhancement in osmotic fragility data for samples collected after 45 days' post exposure.

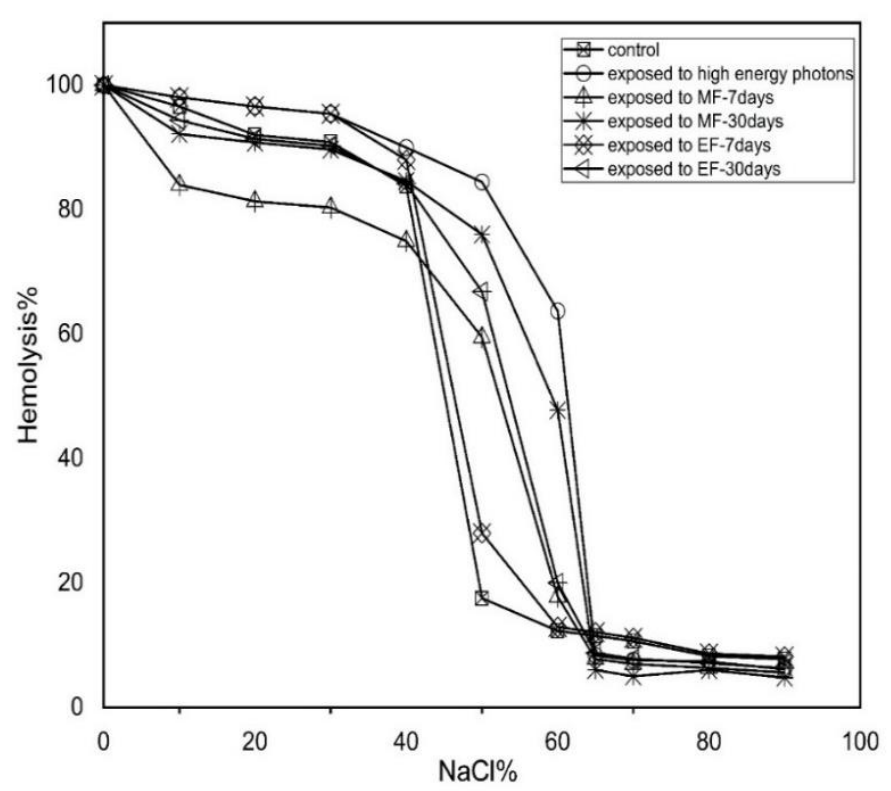

Fig. (3): The variation of hemolysis percentage as a function of $\mathrm{NaCl}$ concentration percentage for blood samples collected directly after exposure



Fig. (4): the variation of hemolysis percentage as a function of $\mathrm{NaCl}$ concentration percentage for blood samples collected 45 days' post exposure

The obtained hemolysis data for blood samples collected directly after exposure and delayed by 45 days' post exposure were differentiated and graphed as a function of $\mathrm{NaCl}$ concentration percentage as presented in Figures (5 and 6). The working on the differential curves is useful for detecting significant elastic parameters such as the concentration at which hemolysis starts (Cs), the maximum hemolysis rate (Cmax), the half maximum width of this peak $\left(\mathrm{W}_{\mathrm{Hmax}}\right)$ which represent the elastic range of the cell membrane. The elastic parameters were calculated from differential graphs and average values are listed in Tables (1 and 2). The shift of main differential peaks to higher or lower concentrations indicates alterations in the uptake of water molecules 
under the osmotic pressure. The obtained data indicated increase of $\mathrm{Cs} \%$ and $\mathrm{Cmax} \%$ relative to control for samples collected directly after exposure with maximum shift for samples exposed to MF-30 days by $71 \%$ and $44 \%$ respectively. The increase of $\mathrm{Cs} \%$ and $\mathrm{Cmax} \%$ relative to control was followed by samples exposed to high energy photons to be $48 \%$ and $35 \%$ Cs\% respectively. Moreover, the value of $\mathrm{WHmax} \%$ represents the rigidity of cell membrane as much its value increase as much the cellular membrane become

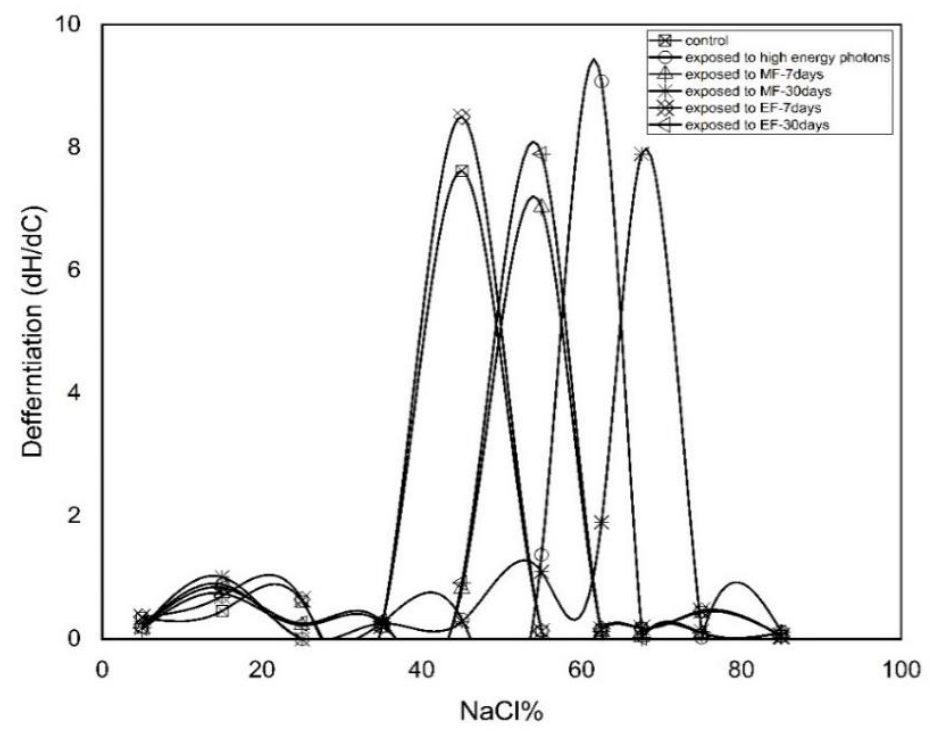

Fig. (5): The differential data plotted as a function of the average $\mathrm{NaCl}$ concentration percentage of samples collected directly after exposure rigid. The obtained data depicted very low width at half maximum for samples collected after exposure to MF-30 days (-30\% than control) and followed by samples collected after exposure to high energy photons (-20\% than control). The data obtained from differential curves for samples collected 45 days after exposure indicated significant enhancement to come closer to the control values except for samples collected after exposure to MF-30 days and high energy photons.

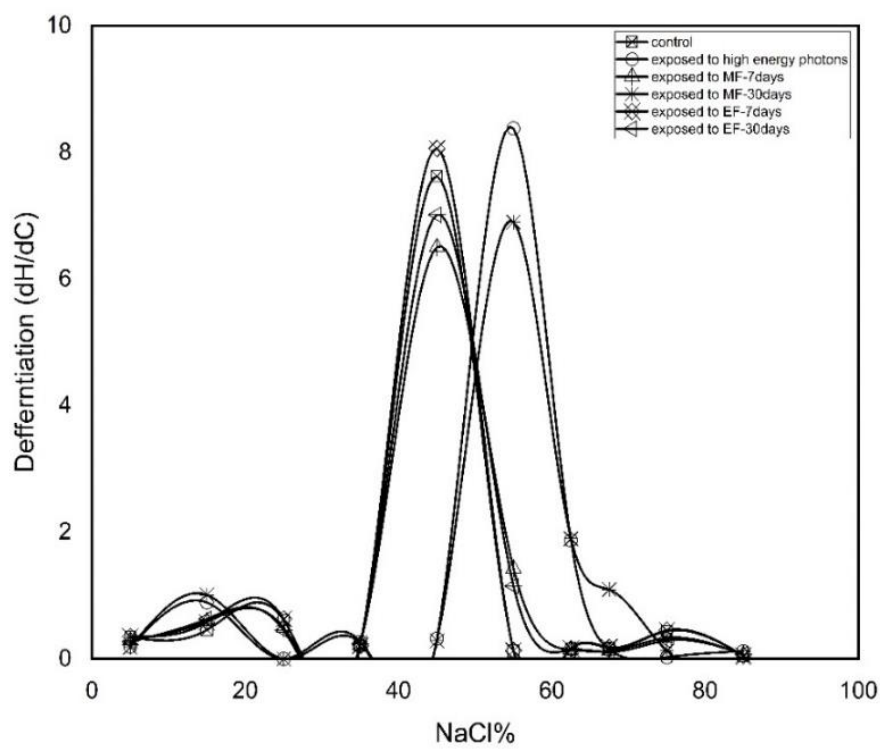

Fig. (6): The differential data plotted as a function of the average $\mathrm{NaCl}$ concentration percentage of samples collected 45 days' post exposure

Table(1): The average values of calculated elastic parameters for samples collected directly after exposure

\begin{tabular}{llll}
\hline Groups & Cs \% & Cmax \% & WHmax \% \\
\hline Control & $35.73 \pm 2.31$ & $45.71 \pm 1.74$ & $10.12 \pm 0.95$ \\
Exposed to high energy photons & $52.92 \pm .36 * *$ & $61.08 \pm 2.42$ & $8.22 \pm 0.65 * *$ \\
Exposed to MF-7days & $47.06 \pm 1.31 *$ & $54.91 \pm 1.33 *$ & $9.88 \pm 0.75 * *$ \\
Exposed to MF-30days & $60.72 \pm 1.88 * *$ & $65.22 \pm 1.95 * *$ & $7.12 \pm 0.56 *$ \\
Exposed to EF-7days & $38.18 \pm 2.01 *$ & $44.37 \pm 1.87 *$ & $10.05 \pm 0.75 *$ \\
Exposed to EF-30days & $44.61 \pm 1.52$ & $55.77 \pm 1.78 *$ & $9.59 \pm 0.51$ \\
\hline
\end{tabular}

* Statistically significant

** Statistically highly significant

Table(2): The average values of calculated elastic parameters for samples collected 45 days' post exposure

\begin{tabular}{llll}
\hline Groups & Cs \% & Cmax \% & WHmax \% \\
\hline Control & $35.23 \pm 1.31$ & $45.41 \pm 1.22$ & $10.32 \pm 0.95$ \\
Exposed to high energy photons & $45.21 \pm 1.03 *$ & $55.29 \pm 2.78$ & $9.52 \pm 0.65 * *$ \\
Exposed to MF-7days & $36.67 \pm 1.75^{* *}$ & $45.62 \pm 1.16^{*}$ & $10.23 \pm 0.75 * *$ \\
Exposed to MF-30days & $46.21 \pm 1.32 * *$ & $55.12 \pm 1.04 * *$ & $9.21 \pm 0.62 *$ \\
Exposed to EF-7days & $35.28 \pm 1.15 *$ & $45.23 \pm 1.02 * *$ & $10.25 \pm 0.95 *$ \\
Exposed to EF-30days & $36.27 \pm 1.05 *$ & $45.29 \pm 1.02 *$ & $9.98 \pm 0.82 *$ \\
\hline
\end{tabular}

* Statistically significant

** Statistically highly significant 
In addition to the viscoelasticity and osmofragility studies the effect of exposure on the biochemical parameters RBCs, Hb, HCT, MCV, MCH, MCHC and WBCs were studied for blood samples collected directly after exposure and delayed 45 days' post exposure as tabulated in Tables(3 and 4) respectively.

The obtained hematological parameters supported the former viscoelasticity and osmofragility results that indicated high shift in the samples collected directly and delayed by 45 days after exposure to MF-30days and followed by exposed groups to high energy photons. The RBCs indices (RBCs count, $\mathrm{MCV}, \mathrm{MCH}$, and $\mathrm{MCHC}$ ) and WBCs counts of samples collected directly after exposure to MF-30 days showed maximum increase relative to the control values by $(15 \%, 14 \%, 5 \%$, and $14 \%$ ) and $15 \%$ respectively. Such increase was followed by RBCs indices (RBCs count, MCV, MCH, and $\mathrm{MCHC}$ ) and WBCs counts for samples collected directly after exposure to high energy photons by $(10 \%, 9 \%, 3 \%$, and $8 \%$ ) and $9 \%$ respectively. Moreover, the samples collected directly after exposure to MF-30 days showed maximum decrease in hemoglobin percentage relative to control one by $-25 \%$. The decreases in hemoglobin percentage was followed for samples collected directly after exposure to high energy photons by $-20 \%$ than control one.

Packing all results together it may lead to the effect of exposure on the macromolecular structure of blood cell membrane as a result of the interference between external electromagnetic signals and metabolic biosignals [33-36]. Such interferences had ability to change the charges distribution outer the cell membrane and produce lose membrane packing properties that lead to make cells stack together and hence its viscoelastic property will be altered [37-40].

Table(3): The average values of biochemical parameters for samples collected directly after exposure

\begin{tabular}{|c|c|c|c|c|c|c|c|}
\hline Groups & Hb (g/dl) & $\begin{array}{c}\text { RBCs } \\
(\text { million/mm3) }\end{array}$ & HCT (vol\%) & $\operatorname{MCV}(\mathbf{f l})$ & MCH (Pg) & MCHC (g/dl) & $\begin{array}{c}\text { WBCs } \\
(\mathrm{million} / \mathbf{m m 3})\end{array}$ \\
\hline Control & $12.03 \pm 0.4$ & $4.61 \pm 0.14$ & $37.90 \pm 1.45$ & $87.96 \pm 2.03$ & $29.1 \pm 0.95$ & $33.65 \pm 0.84$ & $92.87 \pm 2.45$ \\
\hline Exposed to high energy photons & $9.61 \pm 0.24 *$ & $5.06 \pm 0.20 *$ & $30.30 \pm 1.63$ & $96.56 \pm 3.11 *$ & $30.08 \pm 1.19 *$ & $36.93 \pm 0.96$ & $101.95 \pm 3.03$ \\
\hline Exposed to MF-7days & $10.68 \pm 0.49 * *$ & $4.76 \pm 0.11 *$ & $33.65 \pm 2.06 *$ & $90.89 \pm 2.14 * *$ & $29.28 \pm 1.02 *$ & $34.77 \pm 1.03 *$ & $95.97 \pm 4.09 * *$ \\
\hline Exposed to MF-30days & $8.92 \pm 0.43$ & $5.28 \pm 0.31 *$ & $28.11 \pm 1.86 * *$ & $100.67 \pm 3.59$ & $30.45 \pm 0.87 *$ & $38.51 \pm 1.28 * *$ & $106.29 \pm 5.08 *$ \\
\hline Exposed to EF-7days & $11.80 \pm 0.52 *$ & $4.68 \pm 0.21$ & $37.19 \pm 1.84$ & $89.31 \pm 3.12 *$ & $29.08 \pm 0.97 * *$ & $34.16 \pm 1.48$ & $94.3 \pm 3.23 * *$ \\
\hline Exposed to EF-30days & $9.96 \pm 0.36 *$ & $4.79 \pm 0.19 *$ & $31.38 \pm 1.53 * *$ & $91.46 \pm 3.8 *$ & $29.4 \pm 1.07 *$ & $34.99 \pm 1.26 *$ & $96.57 \pm 4.76 * *$ \\
\hline
\end{tabular}

* Statistically significant

** Statistically highly significant

Table(4): The average values of biochemical parameters for samples collected 45 days' post exposure

\begin{tabular}{|c|c|c|c|c|c|c|c|}
\hline Groups & $\mathrm{Hb}(\mathrm{g} / \mathrm{dl})$ & $\begin{array}{c}\text { RBCs } \\
\text { (million/mm3) }\end{array}$ & HCT (vol\%) & $\operatorname{MCV}(\mathbf{f l})$ & MCH (Pg) & MCHC (g/dl) & $\begin{array}{c}\text { WBCs } \\
(\mathrm{million} / \mathrm{mm} 3)\end{array}$ \\
\hline Control & $12.03 \pm 0.40$ & $4.61 \pm 0.14$ & $37.90 \pm 1.45$ & $87.96 \pm 2.03$ & $29.1 \pm 0.95$ & $33.65 \pm 0.84$ & $92.87 \pm 2.45$ \\
\hline Exposed to high energy photons & $10.92 \pm 0.36 *$ & $4.98 \pm 0.22$ & $32.10 \pm 1.65 * *$ & $95.06 \pm 2.91 *$ & $29.88 \pm 1.0 *$ & $36.36 \pm 1.03 * *$ & $100.37 \pm 3.03$ \\
\hline Exposed to MF-7days & $11.69 \pm 0.44$ & $4.69 \pm 0.13 * *$ & $35.78 \pm 1.75$ & $89.42 \pm 2.08$ & $29.19 \pm 0.99 * *$ & $34.21 \pm 0.93$ & $94.42 \pm 4.09 *$ \\
\hline Exposed to MF-30days & $11.31 \pm 0.44 * *$ & $4.88 \pm 0.19$ & $33.22 \pm 1.79 *$ & $93.17 \pm 2.59 * *$ & $29.61 \pm 0.95 *$ & $35.64 \pm 1.05 *$ & $98.38 \pm 5.08 * *$ \\
\hline Exposed to EF-7days & $11.97 \pm 0.46 *$ & $4.65 \pm 0.18 *$ & $37.55 \pm 1.65 *$ & $88.64 \pm 2.57$ & $29.09 \pm 0.96$ & $33.9 \pm 1.16 *$ & $93.59 \pm 3.23 *$ \\
\hline Exposed to EF-30days & $11.73 \pm 0.42$ & $4.69 \pm 0.18 *$ & $35.49 \pm 1.61 *$ & $89.58 \pm 2.98 *$ & $29.19 \pm 1.0 * *$ & $34.26 \pm 1.19 * *$ & $94.58 \pm 4.76 *$ \\
\hline
\end{tabular}

* Statistically significant

** Statistically highly significant 


\section{CONCLUSION}

From the present results it may be concluded that the exposure to electric and magnetic field at extremely low frequency range has hazardous effect not less than the ionizing radiation at very low dose. The exposure to magnetic field has the maximum hazardous effect as compared with other exposed groups and the highest deteriorations were observed after exposure to successive 30 days. The changes in blood viscoelasticity and hematological parameters as a result of the exposure even after 45 days' post exposure support the hazardous effects of such fields. The need of new recommendations for exposure to such fields and frequent blood checkup should be done from time to another specially for residents who expose for long times.

\section{REFERANCES}

[1] Anna Marcinkowska-Gapinska and Honorata Nawrocka-Bogusz.,(2013), "Analysis of the Magnetic Field Influence on the Rheological Properties of Healthy Persons Blood". BioMed Research International Volume 2013, Article ID 490410, 7 pages http://dx.doi.org/10.1155/2013/490410.

[2] Schüz, J.,(2011), "Exposure to extremely lowfrequency magnetic fields and the risk of childhood cancer: Update of the epidemiological evidence. Progr. Biophys. Molec. Biol. 107, 339-342.

[3] Touitou, Y. \& Selmaoui, B., (2012), The effects of extremely low-frequency magnetic fields on melatonin and cortisol, two marker rhythms of the circadian system, Dial. Clin. Neurosci. 14, 381399.

[4] World Health Organization. (2007), Extremely Low Frequency Fields. Environmental Health Criteria Monograph no.238. WHO Press, Geneva, http://www.who.int/peh-

emf/publications/elf_ehc/en (Date of access: 01/02/2015).

[5] Morelli A, Ravera S, Panfoli I, Pepe IM., (2005), "Effects of extremely low frequency electromagnetic fields on membrane-associated enzymes". Archives of Biochemistry and Biophysics; 441: 191-198. PMID: 16126157.

[6] Menon, R., Taylor, R.N., Urrabaz-Garza, R., Kechichian, T., Syed, T.A., Papaconstantinou, J., Saade, G., Boldogh, I., (2013). Reactive oxygen species (ROS) induce DNA damage and senescence in human amniochorionic membranes and amnion cells. Reprod. Sci. 20, 239a-239a.

[7] Uzunboy, S., Cekic, S.D., Apak, R., (2016). Determination of reactive oxygen species induced dna damage using modified cupric reducing antioxidant capacity (CUPRAC) colorimetric method. FEBS J. 283, 397e398.

[8] Wells, P.G., Miller-Pinsler, L., Bhatia, S., Drake, D., Shapiro, A.M., (2015). Reactive oxygen species (ROS) formation, oxidative DNA damage and repair in teratogenesis. Birth Defects Res. Part A Clin. Mol. Teratol. 103, 359e359.

[9] Xu, Z.Z., Fu, W.B., Jin, Z., Guo, P., Wang, W.F., Li, J.M., (2016). Reactive oxygen species mediate oridonin-induced apoptosis through DNA damage response and activation of JNK pathway in diffuse large B cell lymphoma. Leuk. Lymphoma 57, $888 \mathrm{e} 898$.

[10] Yvan Touitou., Brahim Selmaoui., (2012), “The effects of extremely low-frequency magnetic fields on melatonin and cortisol, two marker rhythms of the circadian system". Translational research. Dialogues in Clinical Neuroscience - Vol 14. No. 4.

[11] Alaa. M. Khalil, (2019), "Relative biophysical effects on rat's bone as result of high energy photons and electromagnetic field exposures". Arab J. Nucl. Sci. Appl., Vol. 52, 4, 21-27.

[12] Mai. I. El-kaliuoby, (2019)," A comparative Study Between the Exposures of $6 \mathrm{MeV}$ Photons and 0.3 mT-50 Hz Magnetic Fields in Rat's Liver". Arab J. Nucl. Sci. Appl., Vol. 52, 3, 249-258.

[13] Kabuto, H., I. Yokoi, N. Ogawa, A. Mori and R.P. Liburdy, (2001)," Effects of magnetic fields on the accumulation of thiobarbituric acid reactive substances induced by iron salt $\mathrm{H} 2 \mathrm{O} 2$ in mouse brain homogenates or phosphotidylcholine. Pathophysiology; 7: 283-288.

[14] Jelenkovic, A., B. Janac, V. Pesic, D.M. Jovanovic, I. Vasiljevic and Z. Prolic, (2006)," Effects of extremely low - frequency magnetic field in the brain of rats". Brain Res Bull; 68: 355-360.

[15] Halliwell, B., (2001)," Role of free radicals in the neurodegenerative diseases: therapeutic implications for antioxidant treatment". Drugs Aging; 18: 685-716.

[16] Valko, M., D. Leibfritz, J. Moncol, M. T. Cronin, M. Mazur and J. Telser, (2007), Free radicals and 
antioxidants in normal physiological functions and human disease. Int. J. Biochem Cell Biol; 39: 44-84.

[17] Lee, BC., H. M. Johng, J. K. Lim et al., (2004),' Effects of extremely low frequency magnetic field on the antioxidant defense system in mouse brain: a chemiluminescence study. J Photochem Photobiol B; 73: 43- 48 .

[18] Li Gun, Du Ning., (2017), "Equivalent Permittivity Based on Debye Model of Blood and Its SAR". International Journal of Science, Technology and Society; 5(3): 37-40.

[19] D. Lerche, H. Bamler, W. Kucera, W. Meier, and M. Paulitschke, (1991), "“ "Flow properties of blood and hemoreological methods of quantification," in Physical Characterization of Biological Cells. Basic Research and Clinic Relevance, W. Scutt, H. Klinkmann, '“ I. Lamprecht, and T. Wilson, Eds., pp. 189-214.

[20] Wyszkowska, J., Jędrzejewski, T., Piotrowski, J., Wojciechowska, A., Stankiewicz, M. and Kozak, W., (2018)," Evaluation of the influence of in vivo exposure to extremely low-frequency magnetic fields on the plasma levels of pro-inflammatory cytokines in rats. International journal of radiation biology, 94(10), pp.909-917.

[21] Aziza A. El Saeid., Mona A. Mohamed., (2016), "Effects of Whole-Body Exposure to Extremely Low Frequency Magnetic Field (ELFMF) on Physical and Biological Parameters in vivo Rats". International Journal of Environment, Volume: 05, Issue: 01, Pages: 1-8.

[22] Singh, H., C. Kumar and U. Bagai, (2013). Effect of electromagnetic field on red Blood cells of adult male Swiss albino mice. International Journal of theoretical and applied science 5(1):175-182.

[23] Sani A, Labaran MM, Dayyabu B., (2018), "Effects of electromagnetic radiation of mobile phones on hematological and biochemical parameters in male albino rats". European J Exper Biol.;8(2):11.

[24] Kumari P, Manjula SD, Gautham K., (2016), “In Vitro study of effect of radiation emitted by mobile phone on osmotic fragility and other blood parameters". Res J Pharm Biol Chem Sci.;7(4):1283-1292.

[25] Hashem MA, El-Sharkawy NI., (2009), "Hematobiochemical and immunotoxicological effects of low electromagnetic field and its interaction with lead acetate in mice. Iraqi J Veter Sci.;23(1):105114.

[26] Alghamdi MS, El-Ghazaly NA. (2012), "Effects of exposure to electromagnetic field on some hematological parameters in mice. Open $\mathrm{J}$ Med Chem.; 2:30-42.

[27] Purushothaman G, Gajalakshmi G, Qairunnisa S., (2013), "Evaluation of hematological and biochemical parameters of magnetic field exposed albino rats". Current Trends Biotechnol Pharm.; 7:8873-8916.

[28] H. El-Shanshoury , G. El-Shanshoury , A. Abaza, (2016), "Evaluation of low dose ionizing radiation effect on some blood components in animal model". Journal of Radiation Research and Applied Sciences Xxx 1-12.

[29] Nabila S. Selim., O.S. Desouky., Seham M. Ali., I.H. Ibrahim and Hoda A. Ashry., (2009), "Effect of gamma radiation on some biophysical properties of red blood cell membrane". Romanian J. Biophys., Vol. 19, No. 3, P. 171-185, Bucharest.

[30] Ali Abid Abojassim., Haider Salih Jaffat., Adhraa Baqir Hassan., (2015), "Effects of Gamma Radiation on Some Hematological Parameters in Female Rats". Energy, Environment and Material Science, ISBN: 978-1-61804-352-8.

[31] Mai. I. El-kaliuoby, Ahmed. M. El-Khatib, Khalil, A. M, Mohamed Ahmed Abbas Naim and Malak M. Elmesady. (2017) Monitoring of relative changes in rats' tibia bone characteristics after exposure to $4 \mathrm{kv} / \mathrm{m}-50 \mathrm{hz}$ electric fields", International Journal of Current Research, 9, (12), 62026-62031.

[32] M. Khalil, Ahmed. M. El-Khatib, Moustafa M. Mohamed, Mostafa El-Khatib Hanan. M.Abdulsalam, Gamal D Roston (2016) "Monitoring of Variations in Some Hematological Parameters and Liver Enzymes as a Result of Exposure to 50-Hz Electric Fields" J. Harmoniz. Res. Med. and Hlth. Sci., 3(2), 113-120.

[33] Mai. I. El-kaliuoby, Alaa M. Khalil and Ahmed. M. El-Khatib, (2020) Alterations of bacterial dielectric characteristics due to pulsed magnetic field exposure. Bioinspired, Biomimetic and Nanobiomaterials 9(2): 103-111, https://doi.org/10.1680/jbibn.19.00055

[34] Fadel M.Ali, Osoris W.G, N.Serag, A. M. Khalil (2016) ; "Healing of Guinea Pig Injures Contaminated with Pseudomonas aeruginosa by 
using $0.7 \mathrm{~Hz}$ Square Pulsed Magnetic Field (New Method)" Int. J. Curr. Res. Med. Sci. 2(5): 6-11.

[35] Fadel M. Ali, A. M. Elkhatib, W. M. Aboutaleb, A. M. Abdelbacki, A. M. Khalil and Mai. I. Elkaliuoby (2014) "Control the Activity of Ralstonia Solanacearum Bacteria by Using Pulsed Electric Field" Jokull Journal Vol 64, No. 4; (255-269).

[36] Fadel M. Ali, A. M. Elkhatib, W. M. Aboutalib, A. M. Abdelbacki, A. M. Khalil, and N.Serag. (2013) "Control of the Activity of Pseudomonas Aeruginosa by Positive Electric Impulses at Resonance Frequency" J Am Sci;9(10):120-130]. (ISSN: 1545-1003).

[37] Naglaa M Balabel, Mai I El-Kaliuoby and Alaa M Khalil (2019). Effect of square pulsed magnetic field exposure on growth kinetics of Dickeya solani. Archives of Phytopathology and Plant Protection 52:11-12, 989-1004.
[38] Mai I Elkaliuoby, Ahmed M El-Khatib and Alaa M Khalil (2019). Does Engineering of Nano Shapes Have Antibacterial Synergy with Magnetic Signals Exposure? Surface Innovations, 7(5), 260-267.

[39] Ahmed M El-Khatib, Alaa M Khalil, Mai I Elkaliuoby, Mostafa Elkhatib. (2019). The combined effects of multisized silver nanoparticles and pulsed magnetic field on $\mathrm{K}$. pneumoniae. Bioinspired, Biomimetic and Nanobiomaterials, 8(2), pp. 154-160.

[40] Mai I Elkaliuoby, Alaa M Khalil, Ahmed M ElKhatib and Thanaa I. Shalaby (2018) Synergistic antibacterial effect of silver nanoparticles and extremely low frequency pulsed magnetic fields on Klebsiella pneumoniae. Journal of Applied Biology \& Biotechnology 6(6): 039-045. 